Review Article

\title{
Role of temperature in influenza outbreaks
}

\author{
Sudhir Kumar Ambati*
}

Department of Epidemiology, University of Medicine and Health Sciences, Saint Kitts and Nevis, West Indies

Received: 07 June 2020

Revised: 25 June 2020

Accepted: 26 June 2020

\section{*Correspondence:}

Dr. Sudhir Ambati,

E-mail: sudhirambati@gmail.com

Copyright: () the author(s), publisher and licensee Medip Academy. This is an open-access article distributed under the terms of the Creative Commons Attribution Non-Commercial License, which permits unrestricted non-commercial use, distribution, and reproduction in any medium, provided the original work is properly cited.

\section{ABSTRACT}

Respiratory tract infections are among the most common types of infections, globally. Seasonal variations have been associated with substantial roles in influencing respiratory mortality and morbidity. The effects of seasonal variations of respiratory tract infections are evidenced by the monthly increase in the use of healthcare services and hospital admissions during colder seasons. Influenza outbreaks are associated with worse health problems, which increase the morbidity and mortality rate of high-risk populations. Comparing tropical and colder regions, temperatures are high during summer and lower during winter. Additionally, relative humidity is comparatively higher in winter than in summer. In winters, the indoor humidity is low due to heating facilities, which suggests that cold air outside and dry air inside that occurs during the winter favors the transmission of the influenza virus and thus, triggering a flu infection season.

Keywords: Influenza outbreaks, Temperature, Humidity, Winter

\section{INTRODUCTION}

Globally, the most common types of infections are respiratory tract infections. ${ }^{1}$ Seasonal variation have been associated with substantial roles in influencing respiratory mortality and morbidity. ${ }^{2}$ The effects of seasonal variations of respiratory tract infections are evidenced by the monthly increase in the use of healthcare services and hospital admissions during colder seasons. Influenza outbreaks are associated with worse health problems, which increase the morbidity and mortality rate of highrisk populations. Annual influenza outbreaks cause approximately three to five million incidents of sickness and 250,000 to 500,000 fatalities globally. ${ }^{3}$

Temperature and humidity have been found to have substantial effects on the occurrence of influenza outbreaks. ${ }^{4}$ Although various studies examine the modes of transmission of influenza in colder and tropical regions, the role of temperature in influenza cases and outbreaks still remains unclear. As such, this study aims to answer these questions by providing evidence of whether influenza outbreaks are less in tropical areas than in colder regions. The study will also explore the mechanisms through which temperature and humidity influence survival of influenza virus. In addition, it will compare the regional variability in prevalence of influenza cases and outbreaks in colder and tropical countries.

\section{ROLE OF TEMPERATURE IN INFLUENZA OUTBREAKS}

Influenza outbreaks have been found to spread widely, particularly in the temperate regions. This has even marked wintertime seasonality, where these outbreaks are much detected over a period of two to three months between November to March in the northern regions and between May and September in the southern regions. Influenza outbreaks dominate in tropical and sub-tropical 
areas during certain months of the year. Seasonal influenza in various tropical areas arises during rainy spells. The latest epidemiological studies posit that humidity in the winter increases the persistence rate of influenza virus, making its outbreaks to be severe. ${ }^{5}$

Temperature and humidity are associated with the survival rate of influenza. ${ }^{6}$ Stability of the influenza outer membrane, which protects it during its transmission through the air, depends on temperature. ${ }^{7}$ The relationship between the survival of the influenza virus and the low temperature has been found to dominate in temperate regions. However, in tropical and subtropical regions, there is no enough evidence for their effects on influenza transmission. ${ }^{8}$ Nevertheless, Low temperatures influence influenza outbreaks in some of the tropical and subtropical areas. ${ }^{9}$

An experiment on the influence of humidity and temperature on the influenza outbreak revealed that they have substantial impacts on influenza transmission. ${ }^{10}$ In studies comparing tropical and colder regions, it was observed that relative humidity is comparatively higher in winter than in summer. However, because of heating facilities, the indoor humidity is low. Aerosolized influenza virus is more stable at lower relative humidity. This posits that the cold air outside and dry air inside that occurs during the winter favors the transmission of the influenza virus and thus, triggering a flu infection season. ${ }^{10}$

Generally, influenza was found to spread more in colder regions but was inefficient in warmer and hotter regions. Based on the humidity of the regions, dry conditions favored the spread of transmission of the virus. Furthermore, in experiments on the transmission of the influenza $\mathrm{B}$ virus at low temperatures of $5^{\circ} \mathrm{C}$ and intermediate temperatures of $20^{\circ} \mathrm{C}$ it was found out that the virus spreads faster in low temperatures as compared to higher temperatures. ${ }^{11}$ This implies that cold and dry temperatures favor the spread of human influenza viruses.

\section{MECHANISM ASSOCIATING TEMPERATURE AND HUMIDITY TO INFLUENZA OUTBREAKS}

It is still unclear why the influenza virus is favored by cold and dry conditions. However, numerous studies have demonstrated the mechanism through experimental support. The influenza virus has continuously been found to be more stable at low relative humidity and comparatively unstable at an intermediate relative humidity. ${ }^{11}$ It was also observed that high temperatures prevent the spread of the influenza virus. ${ }^{11}$ The impact of relative humidity on the spread of influenza is mediated by salt concentration. This implies that during high temperatures, evaporation increases salt concentration, which consequently inactivates the virus. On the other hand, when the relative humidity is low, salts in the human body crystallizes out of the solution, which reduces its concentration. This consequently increases the stability of influenza. ${ }^{12}$

Influenza outbreaks have also been found to be more stable in cold regions. ${ }^{13}$ The increased spread of the virus in colder regions may be attributed to increased half-life at low temperatures. It is observed that the influenza virus tends to spread more during cold seasons because they are more persistent within the nasal openings. This is because the epithelial surface of the nasal passages gets cooled by the ambient air. The increased stability of influenza in cold places has also been associated with the decreased activities of proteases. ${ }^{13}$

Furthermore, temperature and humidity significantly affect the host-pathogen equation by distorting vulnerability to influenza infection. ${ }^{14}$ Inhalation of cold air also cools the nasal epithelium, which consequently inhibits mucociliary clearance. ${ }^{15}$ This further hinders phagocytosis by essential immune cells located in the upper nasal airways. It was also found that inhaling cold and dry air for approximately thirty minutes significantly slows down mucociliary clearance. This implies that cold and dry air alters the rheological elements of the mucus. Lower temperatures also slow down the cellular metabolic functions, which consequently reduces the rate of ciliary beats, secretion of mucus, and restricted phagocytosis. ${ }^{16}$ These factors contribute to increased life span of influenza virus.

\section{REGIONAL VARIABILITY IN PREVALENCE OF INFLUENZA CASES IN COLDER AND TROPICAL COUNTRIES}

When the mutual impacts of humidity and temperature are considered in the transmission of influenza, the airborne transmission has been found to be more sensitive than contact transmission. ${ }^{13}$ This is because temperature and humidity vary with seasonal temperature changes. Thus, it has been revealed that the airborne transmission dominates in temperate regions. ${ }^{13}$ However, there is no seasonality of influenza outbreaks in tropical regions because of the reduced variability in temperature and humidity. ${ }^{5}$ This posits that the transmission of influenza in tropical regions is through droplets and contact modes.

Influenza outbreaks are associated with low temperatures, particularly in temperate regions. Influenza outbreaks and cases in temperate regions occur in the southern and northern hemispheres during winters. ${ }^{17}$ It has also been demonstrated that colder regions, low indoor humidity and reduced solar radiation increase the intensity of influenza outbreaks. ${ }^{18}$ In some of the tropical regions, influenza cases are linked to rainy seasons, when outdoor humidity is typically greatest relative to the indoor humidity. Contrary to temperate areas, most of the tropical and subtropical regions experience influenza outbreaks throughout the year. ${ }^{18}$ Various reasons account for the varied seasonality of influenza in some of the tropical regions. For instance, People spend most of their 
time indoors during colds seasons, which in turn increases the contact transmission cases. ${ }^{19}$ However, in tropical regions, rainfall and humidity have been found to be the main factors that favor the transmission of the influenza virus. ${ }^{20}$

\section{CONCLUSION}

The influenza outbreaks have been found to spread widely, particularly in the temperate regions. This has even marked wintertime seasonality, where these outbreaks are much detected over a period of two to three months between November and March in the northern regions and between May and September in the southern regions. Studies revealed that cold and dryness are associated with the increased airborne transmission of influenza virus. Temperature and humidity are associated with the survival rate of influenza. The relationship between the survival of the influenza virus and the low temperature has been found to dominate in temperate regions. However, in tropical and subtropical regions, there is no enough evidence for their effects on influenza transmission. In tropical regions, rainfall and humidity have been found to be the main factors that favor the transmission of the influenza virus.

Funding: No funding sources Conflict of interest: None declared

Ethical approval: Not required

\section{REFERENCES}

1. Jaakkola K, Saukkoriipi A, Jokelainen J, Juvonen R, Kauppila J, Vainio O, et al. Decline in temperature and humidity increases the occurrence of influenza in cold climate. Environmental Health. 2014;13(1):22.

2. Mourtzoukou EG, Falagas ME. Exposure to cold and respiratory tract infections. Int $\mathbf{J}$ Tuberculosis Lung Disease. 2007;11(9):938-43.

3. Gasparini R, Amicizia D, Lai PL, Panatto D. Clinical and socioeconomic impact of seasonal and pandemic influenza in adults and the elderly. Human Vaccines Immunotherapeutics. 2012;8(1):21-8.

4. Park JE, Son WS, Ryu Y, Choi SB, Kwon O, Ahn I. Effects of temperature, humidity, and diurnal temperature range on influenza incidence in a temperate region. Influenza Other Respiratory Viruses. 2020;14(1):11-8.

5. Tamerius J, Nelson MI, Zhou SZ, Viboud C, Miller MA, Alonso WJ. Global influenza seasonality: reconciling patterns across temperate and tropical regions. Environmental Health Perspectives. 2011;119(4):439-45.

6. Soebiyanto RP, Clara W, Jara J, Castillo L, Sorto OR, Marinero S, et al. The role of temperature and humidity on seasonal influenza in tropical areas: Guatemala, El Salvador, and Panama. PloS one. 2014;9(6).
7. Polozov IV, Bezrukov L, Gawrisch K, Zimmerberg J. Progressive ordering with decreasing temperature of the phospholipids of influenza virus. Nature Chem Biol. 2008;4(4):248-55.

8. Shaman J, Pitzer VE, Viboud C, Grenfell BT, Lipsitch M. Absolute humidity and the seasonal onset of influenza in the continental United States. PLoS Biol. 2010;8(2):1000316.

9. Azziz BE, Dao CN, Nasreen S, Bhuiyan MU, Muneer MES, Mamun AA, et al. Seasonality, timing, and climate drivers of influenza activity worldwide. J Infectious Diseases. 2012;206(6):83846.

10. Lowen AC, Steel J. Roles of humidity and temperature in shaping influenza seasonality. J Virol. 2014;88(14):7692-5.

11. Pica N, Chou YY, Bouvier NM, Palese P. Transmission of influenza $\mathrm{B}$ viruses in the guinea pig. J Virology. 2012;86(8):4279-87.

12. Yang W, Elankumaran S, Marr LC. Relationship between humidity and influenza A viability in droplets and implications for influenza's seasonality. PloS one. 2012;7(10).

13. Fuhrmann C. The effects of weather and climate on the seasonality of influenza: what we know and what we need to know. Geography Compass. 2010;4(7):718-30.

14. Cooper GE. Natural killer cell responses to influenza A virus in the human lung (Doctoral dissertation, University of Southampton); 2018:283.

15. Eccles R. Wilkinson JE. Exposure to cold and acute upper respiratory tract infection. Rhinology. 2015;53(2):99-106.

16. Boer VDC, Muller SH, Noort VDV, Olmos RV, Minni A, Parrilla C, et al. Effects of heat and moisture exchangers on tracheal mucociliary clearance in laryngectomized patients: a multi-centre case-control study. European Archives Otorhino Laryngology. 2015;272(11):3439-50.

17. Kenah E, Chao DL, Matrajt L, Halloran ME, Longini JIM. The global transmission and control of influenza. PloS one. 2011;6(5).

18. Chong KC, Goggins W, Zee BCY, Wang MH. Identifying meteorological drivers for the seasonal variations of influenza infections in a subtropical city Hong Kong. Int $\mathbf{J}$ Environmental Res Public Health. 2015;12(2):1560-76.

19. Gao X, Wei J, Cowling BJ, Li Y. Potential impact of a ventilation intervention for influenza in the context of a dense indoor contact network in Hong Kong. Sci Total Environment. 2016;569(11):373-81.

20. Moura EA. Influenza in the tropics. Current Opinion Infect Dis. 2010;23(5):415-20.

Cite this article as: Ambati SK. Role of temperature in influenza outbreaks. Int J Community Med Public Health 2020;7:3259-61. 